\title{
TOWARDS SUSTAINABILITY: AN ESSENTIAL DEVELOPMENT FOR EUROPEAN AGRICULTURE
}

\author{
U. MERZ \\ Pathology Group, Institute of Plant Sciences, \\ Swiss Federal Institute of Technology, CH-8092 Zurich, Switzerland
}

\begin{abstract}
In many European countries intensification of agriculture, especially after the Second World War, has led to a massive increase in productivity but also to a wide range of problems with which we are confronted today such as environmental pollution. Serious attempts to incorporate the environment into agricultural policy began only recently. One of the most important steps towards sustainable agriculture is the shift from the traditional price support system - which favours intensive production - to direct payment based on environmental considerations supporting the primary producers. Further, 'green' taxes will be charged increasingly on environmentally harmful products and methods ('polluter pays' principle). Financial support for ecological plant and animal production is growing. Keywords:Intensification, oversupply, direct payment, ecological farming
\end{abstract}

\section{INTRODUCTION}

This century has seen an enormous increase in agricultural production, especially after the 2 nd World War. At the end of the War, there was a widespread concern about food security - particularly as the West and the East looked suspiciously at each other. As a consequence, a huge investment in agriculture research and development and in subsidies was initiated. Production was supported, at any cost, mostly through price support mechanisms. Cereal production, for instance, increased worldwide from 950 million tons to about 1800 million tons between 1960 and 1986 (Weber 1994). More than $80 \%$ of this increase is accounted for by the introduction of better methods of agriculture and crop production. In Europe, the cereal area has even diminished within this period. New high-yielding varieties were used in monoculture with a back-up of high inputs, fertilizer and pesticides, to support these 'super'-plants. Wheat yield in Europe has more than quadrupled since the beginning of this century.

\section{Energy}

\section{THE OTHER SIDE OF THE COIN}

We should be aware, that the intensification of agricultural production in this century was possible only through the availability of energy from fossil fuels but we know also (for example, from the 'Club of Rome') that our resources are limited. The energy consumption in the life-span of the present generation is thought to be equal to that of all previous generations put together. The greater part of that goes into the industrialised countries. Our daily per capita energy input is $4-5$ times the amount of that in developing countries, caused by energy input of agriculture production and food processing (Weber 1994). Although the proportion of agriculture to total consumption is decreasing the absolute numbers have increased: in Switzerland, the need for fuel rose from 20 litres/ ha before the War to 150 litres/ha at the beginning of this decade.

\section{Impact on the environment}

To illustrate the current situation: In Europe, wheat production is only $15 \%$ of world production but needs $85 \%$ of the global pesticide input for wheat. Pesticide and antibiotic residuals in food and drinking water are a permanent issue in public discussion. Pimentel et al (1991) estimated a total of US \$2155 million per year in the USA caused by the social and environmental impact of pesticides. More than half of the costs go into water quality 
surveys followed by an amount of 250 million for the consequences of the toxic effects on humans. About 1/5 of the top soil used in agriculture has been lost in the last twenty years, due to erosion.

\section{Over-production}

Massive over-production in Europe and the US had many serious consequences, including the famous storage 'Mountains' of wheat, butter and meat. Imagine a butter 'mountain' with a volume of $200,000 \mathrm{~m}^{3}$ - corresponding to a building with a square base of $20 \times 20 \mathrm{~m}$ and a height of $500 \mathrm{~m}$. More than half of the 29 billion ecu spent on agriculture in the EU is sucked in by over-production. One consequence was that Europe and the US sought to increase the range and size of their export markets. The poor countries ran into the negative effects of food dumping and also into debt problems on loans from the industrialised countries.

\section{Resistance of control targets}

Hundreds of pests, fewer pathogenic fungi and some weeds have become partially or totally resistant to chemical pesticides in the last decades. This has caused and will cause many problems in plant protection as the time needed today for the development of a new chemical is 10-12 years with costs of about US \$150 million.

\section{Uniformity}

The intensification of agricultural production has contributed to the extinction of a terrifyingly large number of organisms. In today's monoculture systems, only a few varieties are cropped within each species, providing only a narrow genetic base.

\section{A NEW AGRICULTURAL APPROACH}

In the eighties, many of these problems became so obvious and dealing with their impact so difficult and expensive, that politicians had no choice but to look for new ways out of this situation. The 'Den Bosch Declaration on Sustainable Agriculture and Rural Development' (SARD), worked out in a FAO conference in 1991 in the Netherlands, states that: "It has been shown in the industrialized world that agriculture production can be greatly increased if the non-agricultural sectors of the economy provide, in return, the means to do so. However, the intensification has often been accompanied by a large demand on non-renewable resources, environmental pollution, problems of waste disposal, an accelerated rural exodus and the development of unsustainable production patterns. The challenge for the world is to learn from the past experience and to do better, in reconciling further development needs with environment protection requirements." And in the list of the pre requisites it stresses: "Agriculture, both in the developed and in the developing world, should be restructured in such a way that demands of sustainability will be met." Sustainability became a principal keyword in the global frame of the UNCED (UN-Conference on Environment and Development) in Rio in 1992. This Conference marked a turning point in international efforts to tackle the root causes that underlie the continuing degradation of the global environment.

Serious attempts to incorporate the environment into agricultural policy began only recently. One of the most important steps towards a sustainable agriculture is the shift from the traditional price support system - which favours intensive production - to direct or 'compensatory' payments based on environmental considerations and extensification.

\section{European Union}

In the European Union a major change in philosophy and application was initiated in 1992 with the reformation of the 'Common Agricultural Policy'. The aims were to:

- make European production more competitive generally through price reductions while at the same time compensating farmers for income loss, provided they contribute towards reducing oversupply. It was a contradiction that while the European taxpayer was paying more and more money to support the CAP, farmers' incomes were falling due to the pressure that surplus stocks were putting on prices. - ensure that sufficient agriculture was maintained in order to avoid rural depopulation - take account of the environment in agriculture and agricultural policy.

An important part of the new policy was the 'set-aside'-programme, whereby a certain percentage of land is taken out of production. This measure allowed a better control of the quantities coming onto the market and helped, together with price 
reductions, to bring the key markets back into equilibrium and reduce markedly the public (intervention) stocks (Table 1).

TABLE 1: Percentage of the 'set-aside'-area in the EU countries and its effect in the cereal intervention stock.

\begin{tabular}{lccc}
\hline & 1992 & 1994 & 1996 \\
\hline Cereal area (mill. ha) & 38.2 & 34.8 & 36.9 \\
'Set aside' rate (\%) & 0 & 15 & $10^{1}$ \\
Intervention stock (mill. t) & 30 & 9.7 & 5.2 \\
\hline
\end{tabular}

${ }^{1} 5 \%$ for 1997 to allow stocks to rise

The main effect of the CAP reform was a reduction of the oversupply. However positive effects on the environment were only little so far. As farmers used less pesticide on 'set-aside' land this programme had some positive side effect on the overall pesticide input. But with the decreasing compulsory rate of 'set-aside' land, fungicide sales have again increased.

It was also planned to give direct support to environment-friendly projects via the socalled 'accompanying measures'. With a budget of $3 \%$ of the total agricultural budget, which accounted for $50 \%$ of the EU's total budget in 1995, not much can be expected from these measures. A few environmental opportunities have been created as in the case of beef production where results can be expected from extensification due to limits imposed on payments per hectare: 2 large cattle units/ha in 1996 as against 3.5 in 1992. Regional programmes for the promotion of integrated pest control and other environmentally friendly production techniques are co-financed by the EU. Organic farming is the focal point of Austria's sustainable agriculture objectives. The number of organic farms boomed from 6,000 to 23,000 (9\% of total farms) between 1992 and 1995. Sweden and Denmark plan to introduce environmental charges on fertilizers and pesticides. Holland has already introduced a fertilizer/farm manure-tax: Based on farmers balance on mineral input/output and an additional 'free' amount, fixed yearly by the state, a substantial fine will be charged if inputs exeed the allowed maximum. These restrictions concern mostly the pigmeat producers. EU-wide pesticide legislation and market regulations are also under reform.

The chemical industry, however, seems to have a different view of these basically environmentally-positive effects initiated by the CAP reform. As already mentioned, sales of crop protection products in the West European market, which represents $25 \%$ of the world market, dropped after 1992 but recovered in 1994 and 1995, mainly because of fewer planting restrictions. Comment on this development in the 'Annual Report, ECPA, 1995-96': ".... This was the second year of recovery from the negative impact of EU CAP reforms of 1992, which resulted in demand for crop protection products falling one-fifth...". It was also concluded that the farmers had regained confidence in the market and readily adopted preventive spraying programmes rather than the reduced rate application treatments utilised in the last few years.

\section{Switzerland}

As a non-EU member Switzerland faces increasing problems in the European market. And like all other European countries, Switzerland has to deal with environmentally-negative aspects of high-input, intensive production and oversupply. In addition, prices for agricultural products are higher than elsewhere.

It was also in 1992 that the government decided to reform the agricultural policy and to separate the instruments controlling prices and incomes. The needs were to:

- reduce prices to competitive levels while

- maintaining farm incomes

- meeting the public demands for environmentally acceptable methods of production 
- $\quad$ supporting a decentralised, rural population

Two major regulations were applied in 1993 which introduced direct payments to all farmers and encouraged ecologically orientated agriculture. Today, the farmer's income is composed mainly of:

a) a direct payment for living support with higher rates for alpine farmers

qualification: - farm size between 9-50 ha

- staff size of no more than 7

- limited number of farm animals

- depending on region or location

b) a premium for the application of ecological sound production methods

requirements: - conservation compensation (extensive meadows, hedges, high-stemmed trees)

- maintenance of farm animals under specific housing conditions

- Integrated Production (IP)

- Organic agriculture (BIO)

c) sale of products

A national network of 200 pilot farms was established in 1991 to help with research for, and implementation of, the regulation on ecological production (IP + BIO). The premium should encourage sustainable farming, particularly with respect to soil fertility and increased biodiversity leading to increased natural regulation. More and more farmers adapted their production systems to IP and BIO. This development forced the government to raise the total premium amount each year to avoid discouraging farmers (Fig. 1). The amount of 136 million SFr. in 1994 was composed of $40 \%$ for conservation, $5 \%$ for animal welfare, $51 \%$ for IP and $4 \%$ for BIO. In 1996, out of the total number of Swiss farms, $62 \%$ were registered as IP and $7 \%$ as BIO.

To reduce the oversupply in cereals, an 'Extenso' scheme was also introduced in 1992. Wheat or barley produced without fungicides, insecticides or growth regulators were entitled to a state contribution of SFr 800/ha. This amount made 'Extenso' very attractive to farmers: about $60 \%$ of the barley crop and $35 \%$ of wheat are now produced under this scheme. As variety mixtures fit perfectly into the 'Extenso' scheme, their

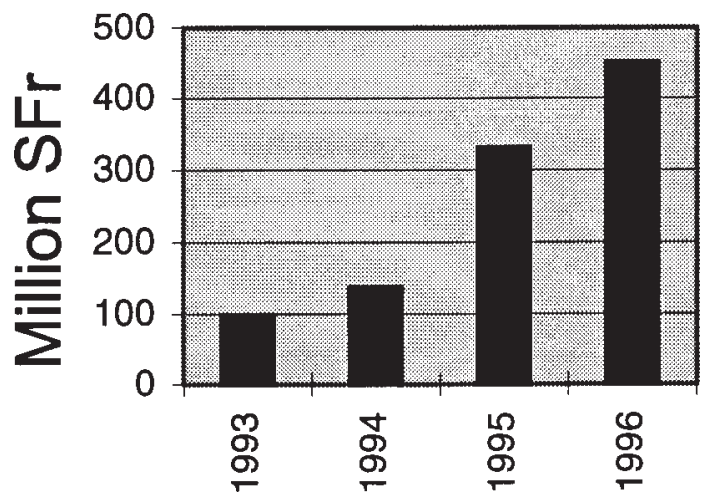

FIGURE 1: Total premium amount for the application of ecologically sound

importance has also increased since 1992 . About $20 \%$ of the barley area and $12 \%$ of the wheat area (both mainly winter crops) are now cropped with mostly 2-component mixtures. 'Extenso' cereals yield 10-15\% less but differ little in quality from the others. As a consequence, turnover in the CCP market for cereal production, the biggest in Switzearland, has dropped from 49 million SFr. in 1991 to 41.4 million SFr. in 1995. Although the total amount of a.i. of CPP for all crops has also decreased, the overall 
turnover remained stable (about 130 million SFr.).

\section{OUTLOOK}

The different reforms in agricultural policy have been an important first step towards sustainability. However, to reach the goal they have to go much further. The shift from price support to direct payment should be continued and support made mainly conditional on environmental considerations. Preventive or calendar treatment should be abandoned and replaced by an IPM system in all crops. In Switzerland, the government expects most farmers to have adapted their production system either to IP or BIO by the year 2000 as a reaction to further planned policy changes in direct payments and eco-farming premiums. Investment in appropriate $R \& D$ programmes should provide the right measures for optimizing food production in environmentally-sound systems to ensure the demand for food for the coming generations. We have to introduce an agriculture that is viable from an environmental standpoint - an agriculture that we can pass on to future generations with pride. And last but not least, a better integration of the environment into major economic policy areas has to be ensured.

\section{REFERENCES}

Pimentel, D., MacLaughlin, L., Zepp, A., Lakitan, B., Kraus, T., Kleinman, P., Vacini, F., Roach, W.J., Graap, E., Keeton, W.S. and Selig, G., 1991. Environmental and economic effects of reducing pesticide use. BioScience 41/6: 402-409.

Weber, A., 1994. Population growth, agricultural production and food supplies. Pp 1-42. In: Crop Production and Crop Protection. Estimated Losses in Major Food and Cash Crops. E.C. Oerke, H.W. Dehne, F. Schönbeck and A. Weber (Eds); Elsevier, Amsterdam, Holland.

Further data presented in this paper originated from numerous articles in national and international journals, EU Internet databases (http://europa.eu.int), own data and personal communications. For detailed information please contact the author. 